\title{
A diligência do Estado na educação e o desapego ao que é público: um ensaio antropológico e político da frenética urbanidade da cidade do Rio de Janeiro Julio Cesar Roitberg
}

Aristóteles Berino, em A economia política da diferença, apresenta os cotidianos de uma escola de educação básica do Rio de Janeiro através de uma narração em que os comentários, as imagens, as letras de poesia e de músicas dão um toque cinematográfico ao seu texto. Já no sumário pode-se perceber, na escolha dos títulos, o toque de escritor, enquanto caligrafia esteticamente produzida: Território, Governo, Alma, Paixão. Cada evolução de pensamento, em sua narrativa, corresponde ao diálogo necessário com a respectiva fotografia que registra os cotidianos da escola praticada: Dissensão, Vértice, Cavidade, Excrescência, Extremidade, Escrituras, Mirante.

Ao assumir a escola enquanto espaço de formação, o autor tensiona os materiais pedagógicos utilizados pela Secretaria Municipal de Educação do Rio de Janeiro, considerando a relação estabelecida entre os atos de currículo e governamentalidade (p. 64-103) e muitas das relações de poder inerentes ao processo de socialização na constituição da história. Para o autor:

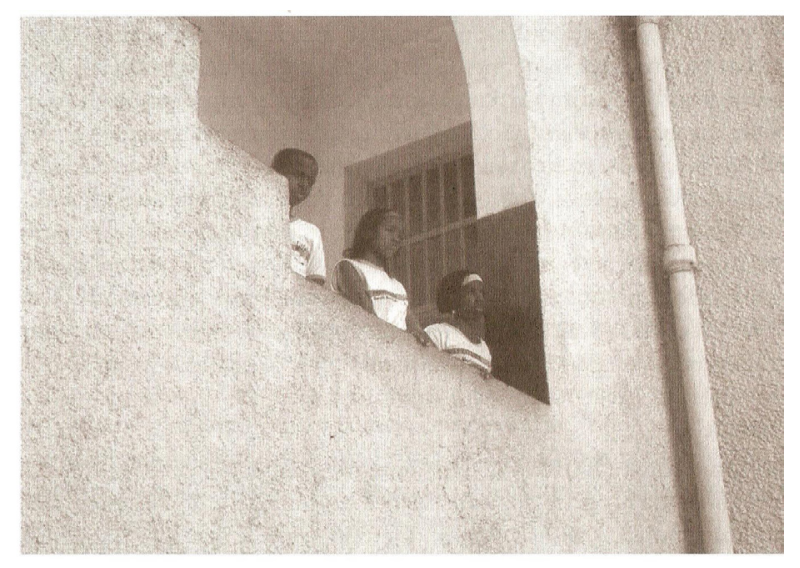

[...] o governo da vida implica a confecção conjunta de pensamentos e atitudes, uma produção organizada e compartilhada de valores e gestos no extenso domínio da existência. [...] O poder acontece, portanto, quando uma ação pode dirigir outra ação. Este constitui o ângulo crítico da minha reflexão sobre a adoção de uma política de reconhecimento da diferença na rede de ensino da prefeitura do Rio de Janeiro." (p. 67).

Berino, aproximando-se e se afastando em suas narrativas, de seus alunos, dos professores e da direção escolar, permite o desvelar do currículo praticado, de onde subjaz o tensionamento da prática pedagógica. Sabedor de que os professores atuantes na educação básica veem-se, a cada ano, com maior intensidade, embalados por dezenas de projetos, o autor subsidia a compreensão 
de que se existe uma obrigação em seguir suas orientações, elas são tão difusas que quase não são percebidas, mesmo quando se trata de algo que conte com a adesão voluntária ou quando esta é compulsória por parte dos educadores.

Conforme as conclusões de Roitberg (2011), muito além dos projetos, multiplicar saberes nos tecidos da educação transcende o simples exercício de planejar atividades em grupos ou realizar um trabalho interdisciplinar. Tal modelo curricular, ainda que inter, continua disciplinar, na tentativa, pela escola-projeto, de formatação (ou deformação), promotora do isolacionismo através da divulgação de informações, da distribuição de conhecimentos há muito fracassada. A contrapelo, faz-se necessário lançar mão, cada vez mais, das referências mais diversas para entender a contemporaneidade. "Essa intenção de constranger a relação educativa a uma atividade assistida e manipulada pelo Estado encontra na autoridade do discurso competente um importante mecanismo de conversão" (Berino, 2007, p. 125). Cumprindo o ideário neoliberal, todos estes projetos enfatizam a preparação para o exercício da cidadania, para a inserção no mercado de trabalho e compreensão dos modernos códigos da comunicação. Não se enxerga em tais propostas uma clara preocupação de algo que não diga respeito diretamente à economia, traduzida por desenvolvimento, já que, segundo Berino (2007), “[...] a educação experimenta agora um critério de valor que tem significado a sua mercantilização e uma particular vulgarização para as camadas sociais menos favorecidas economicamente."(p. 165). O educando é visto como um ser atuante, um agente do desenvolvimento e o professor, alguém para orientá-lo em sua formação.

Em "A economia política da diferença", Berino, ao desvelar as estratégias de governo da população por trás de um discurso apresentado no projeto da Secretaria Municipal de Educação "Multieducação: Núcleo Curricular Básico" (Rio de Janeiro, 1996), implantado nas escolas da rede de ensino, efetua um corte cirúrgico que permite a visualização dos nódulos nevrálgicos do poder instaurados e disseminados de maneira esparsa nos aparelhos do estado. Desta forma, o autor justifica a necessidade em se discutir a "diligência do Estado na educação nesse instante mesmo em que parece demonstrar seu desapego em relação ao que é publico.” (p. 67).

A governamentalidade (p. 64-71) transparece nos atos e nos discursos, expondo suas contradições, assim como as do próprio autor que se descobre homem em meio a uma identidade profissional e que rejeita a sujeição sem que se esgotem as possibilidades críticas. Usando este mote, Berino discorre sobre as categorias sociológicas de "cidade", "violência”, "cultura", "identidade”, fazendo o leitor aproximar os olhos, assim como se afastar do objeto, ou, ainda, ampliar a objetiva a fim de não perder os detalhes que fazem a diferença quando diante de imposições burocráticas pouco percebidas no ambiente educacional, ainda mais em se tratando de um currículo que, além de contribuir para “(...) que a desigualdade resulte também de uma determinada produção identitária 
nas escolas." (p. 81), já que "os desiguais pela pobreza precisam acreditar que são medíocres e incompetentes, e que por isso são pobres." (p. 81), pretende a regulação urbana da Cidade do Rio de Janeiro, postulante ao estágio de "cidade-empresa" - citação ao conceito do sociólogo e economista Carlos Vainer -, um “espaço imanente de conflitos” (p. 146) a serviço dos imperativos da economia globalizada: os desejos de usar um tênis de marca cobiçada são alimentados tanto pelo aluno de Vila Kennedy (p. 78), quanto pelas meninas do Leblon.



Quando um adolescente - público alvo predileto das campanhas publicitárias - não tem condições de usar uma camisa "de marca", ou um tênis "maneiro", comprando em uma loja de Ipanema (bairro "nobre" do Rio de Janeiro) - se quiser optar pelos caminhos da "legalidade" - ou ele adquire um similar em um shopping da Baixada (região periférica) ou vai direto ao "camelô", dando "o pulo do gato".

Conforme lembra Berino (2007), o tênis Nike, essencialmente americano, não possui fábrica alguma nos Estados Unidos, já que seu processo de fabricação utiliza "plataformas de exportação e mão de obra barata”, principalmente a asiática (2007, p. 43). A naturalidade deste trânsito de mercadorias nas metrópoles é assegurada pelo "meio técnico-científico informacional” em nosso cotidiano.

Amizade, para as juventudes, é mais que números de contatos nas redes sociais, para os quais enviam mensagens. Como fugir da ótica adulta, alienígena diante de sua linguagem, de suas músicas, de seus signos espalhados e debochadamente expostos às câmeras, atualizadas em suas tecnologias de controle e vigilância? Tentando circunscrever suas produções culturais, ao reproduzir que é necessário ter a consciência de seu quadrado, o batidão rola solto na madrugada, unindo o feio da periferia ao bonito da zona sul do Rio de Janeiro (ROITBERG, 2011). Mas é necessário ponderar sobre o fato de que é: 
o risco de tantos contatos que provoca-nos hoje a narrativa de que vivemos a idiossincrasia da diferença e a produção de uma coreografia urbana, que delimita através do reconhecimento das culturas. Desta forma, as identidades distinguem e nos ajudam a estimar cada um dos habitantes da cidade acomodados a um lugar. São os sinais indicativos do pertencimento $[. .$.$] ( p. 74)$

Brincadeiras, zoação, gritos, azaração, movimentos sensuais, piercings, tatuagens, pichação, danças, gestos adquirem ressignificações quando superexpostos pelas mídias massivas. Além de informar o que é de relevo social, ultrapassam tal função (ROITBERG, 2011). Para isto vale a advertência de Berino (2007) acerca da "fabricação, através do arranjo discursivo que dispõe de uma consciência apropriada ao embaraço provocado pelas novas razões da pobreza [que] se estabelecem nas grandes cidades." (p. 75).

Analisando o Multieducação e as implicações daquilo que se apresenta como "um estudo sobre as políticas identitárias desenvolvidas para a rede escolar no município do Rio de Janeiro (...)” (p. 19), Berino não permanece neste âmbito da crítica: ele resvala para um ensaio antropológico e político da frenética urbanidade da cidade do Rio de Janeiro “(...), movida preferencialmente com a erupção dos seus residentes mais atingidos pela impossibilidade de extrair um benefício comum dos projetos de integração a uma ordem mundializada pelo capital." (p. 146). No lugar de uma apologia à modernidade tardia, o autor reitera a declaração de Marx e Engels de que "a história de toda a sociedade até hoje é a história de luta de classes" (p. 134).

Assim como em outras obras do autor, o leitor encontra em A economia política da diferença um rico material de pesquisa que não se restringe ao âmbito da educação. Sem dúvida, é uma obra a ser referenciada por quem que discute a heterogeneidade cultural no cotidiano escolar à luz do currículo praticado, às voltas com as políticas identitárias do Estado.

\section{REFERÊNCIAS}

BERINO, A. P. A economia política da diferença. Rio de Janeiro: Cortez, 2007

BERINO, A. P. A economia política da diferença. Rio de Janeiro: Cortez, 2007.

ROITBERG, J. C. O que levo do Barão: a alegria do estar junto e as juventudes multiplicando saberes nos espaços de educação. Julio Cesar Roitberg, 2011. 142 fl. Il. [Dissertação de mestrado - Universidade Federal Rural do Rio de Janeiro] http://www.ufrrj.br/posgrad/ppgeduc/paginas/ docs_dissertacao/2011/Julio_Cesar_Roitberg.pdf Acesso: 21/01/2012 